\title{
Toward Reliable Uptake Metrics in Large Vessel Vasculitis Studies
}

\author{
Gijs D. van Praagh ${ }^{1, *}++^{\mathbb{D}}$, Pieter H. Nienhuis ${ }^{1,+}+^{\mathbb{D}}$, Daniel M. de Jong ${ }^{1}$, Melanie Reijrink ${ }^{2}$, \\ Kornelis S. M. van der Geest ${ }^{3}$, Elisabeth Brouwer ${ }^{3}$, Andor W. J. M. Glaudemans ${ }^{1}$ (D), Bhanu Sinha ${ }^{4}$ (D), \\ Antoon T. M. Willemsen ${ }^{1}$ and Riemer H. J. A. Slart ${ }^{1,5}$ (i)
}

Citation: van Praagh, G.D.; Nienhuis, P.H.; de Jong, D.M.; Reijrink, M.; van der Geest, K.S.M.; Brouwer, E.; Glaudemans, A.W.J.M.; Sinha, B.; Willemsen, A.T.M.;

Slart, R.H.J.A. Toward Reliable Uptake Metrics in Large Vessel Vasculitis Studies. Diagnostics 2021, 11, 1986. https://doi.org/10.3390/ diagnostics11111986

Academic Editor: Rasmus Sejersten Ripa

Received: 9 September 2021

Accepted: 21 October 2021

Published: 26 October 2021

Publisher's Note: MDPI stays neutral with regard to jurisdictional claims in published maps and institutional affiliations.

Copyright: (c) 2021 by the authors. Licensee MDPI, Basel, Switzerland. This article is an open access article distributed under the terms and conditions of the Creative Commons Attribution (CC BY) license (https:/ / creativecommons.org/licenses/by/ $4.0 /)$.
1 Department of Nuclear Medicine and Molecular Imaging, University Medical Center Groningen, University of Groningen, 9700 RB Groningen, The Netherlands; p.h.nienhuis@umcg.nl (P.H.N.); daniel.m.dejong@gmail.com (D.M.d.J.); a.w.j.m.glaudemans@umcg.nl (A.W.J.M.G.); a.t.m.willemsen@umcg.nl (A.T.M.W.); r.h.j.a.slart@umcg.nl (R.H.J.A.S.)

2 Division of Vascular Medicine, Department of Internal Medicine, University Medical Center Groningen, University of Groningen, 9700 RB Groningen, The Netherlands; m.reijrink@umcg.nl

3 Department of Rheumatology and Clinical Immunology, University Medical Center Groningen, University of Groningen, 9700 RB Groningen, The Netherlands; k.s.m.van.der.geest@umcg.nl (K.S.M.v.d.G.); e.brouwer@umcg.nl (E.B.)

4 Department of Medical Microbiology and Infection Prevention, University Medical Center Groningen, 9700 RB Groningen, The Netherlands; b.sinha@umcg.nl

5 Department of Biomedical Photonic Imaging, University of Twente, 7500 AE Enschede, The Netherlands

* Correspondence: g.d.van.praagh@umcg.nl; Tel./Fax: +31-50-361-70-47

+ G. D. van Praagh and P. H. Nienhuis equally contributed to the manuscript.

\begin{abstract}
The aim of this study is to investigate the influence of sex, age, fat mass, fasting blood glucose level (FBGL), and estimated glomerular filtration rate (eGFR) on blood pool activity in patients with large vessel vasculitis (LVV). Blood pool activity was measured in the superior caval vein using mean, maximum, and peak standardized uptake values corrected for body weight (SUVs) and lean body mass (SULs) in 41 fluorodeoxyglucose positron emission tomography/computed tomography (FDG-PET/CT) scans of LVV patients. Sex influence on the blood pool activity was assessed with t-tests, while linear correlation analyses were used for age, fat mass, FBGL, and eGFR. Significantly higher SUVs were found in women compared with men, whereas SULs were similar between sexes. In addition, higher fat mass was associated with increased SUVs ( $\mathrm{r}=0.56$ to 0.65 ; all $p<0.001$ ) in the blood pool, but no correlations were found between SULs and fat mass $(\mathrm{r}=-0.25$ to -0.15 ; all $p>0.05)$. Lower eGFR was associated with a higher FDG blood pool activity for all uptake values. In FDG-PET/CT studies with LVV patients, we recommend using SUL over SUV, while caution is advised in interpreting SUV and SUL measures when patients have impaired kidney function.
\end{abstract}

Keywords: vasculitis; fluorodeoxyglucose F18; positron emission tomography computed tomography; standardized uptake values; lean body mass

\section{Introduction}

Semi-quantitative measurements, e.g., the mean or maximum standardized uptake value (SUV), are increasingly being used and recommended in 2-[fluorine-18]-fluoro-2deoxy-D-glucose positron emission tomography (FDG-PET). The SUV is a simple, unitless metric in which the amount of activity within a volume of interest (VOI) in the PET scan is corrected for the injected radiotracer dose and for body weight. In 1993, Zasadny et al. recommended to use the SUV normalized to lean body mass (LBM), referred to as SUL, due to the SUV's dependency on body weight [1]. FDG uptake in fat is low, whereas body weight highly depends on fat [2]. This would imply that correcting for body weight is inadequate and might lead to different treatment approaches between patients with different fat percentages or to erroneous patient monitoring when fat mass changes. Thus, 
using SUL should result in more consistent quantification of the resulting signal. SUV and SUL are calculated as follows:

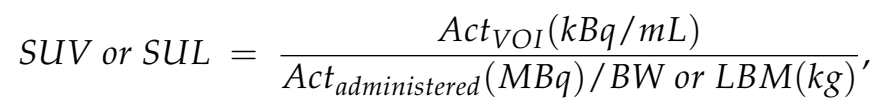

where $A c t_{V O I}$ is the activity concentration measured in the VOI; the Act administered is the net administered activity corrected for physical decay of FDG to the start of the acquisition; and $1 \mathrm{~mL}$ of tissue is assumed to weigh $1 \mathrm{~g}$ [3].

The most recent EANM guideline for oncological imaging recommends quantifying the tracer uptake by using SUL [3]. However, in PET imaging of inflammatory disorders, such as large vessel vasculitis (LVV), there is no consensus on the best correction method of FDG uptake [4,5]. Most (recent) LVV PET studies only used SUV as quantitative scoring method and did not mention SUL [6-9].

Furthermore, recent literature demonstrated differences in glucose metabolism with sex and age, possibly influencing the uptake activity during scanning [10]. Besides, impaired renal function slows down the clearance of FDG and thus may increase the blood pool activity at the standard $60 \mathrm{~min}$ acquisition time [11]. Guidelines consider this issue when intravenous contrast material has to be applied, but do not advise for FDG [3,4].

Although these semi-quantitative measurements are mainly used in research settings of patients with LVV so far, it is of utmost importance that these values are correct and reliable to potentially use FDG PET to achieve optimal diagnosis, therapy monitoring, and consistent treatment strategies. Therefore, the aim of this study was to investigate the influence of sex, age, fat mass, fasting blood glucose level (FBGL), and kidney function on blood pool SUVs and SULs in patients with large vessel vasculitis.

\section{Materials and Methods}

\subsection{Patients and Scan Acquisition}

In this study, electronic patient files of patients with LVV were retrospectively checked for the presence of a FDG PET/CT scan before start of treatment. All patients signed informed consent as part of a prospective cohort study, which was approved by the institutional review board of the UMCG (METc 2010/222) [12]. The LVV diagnosis was made by a rheumatologist. This diagnosis had to be manifested for at least 6 months after initial presentation.

All scans were performed using an integrated PET/CT system (Biograph mCT 40 or 64-slice or Vision; Siemens, Knoxville, TN, USA). The FDG-PET/CT procedure was performed according to the EANM guidelines, which included at least $6 \mathrm{~h}$ fasting prior to FDG injection ( $3 \mathrm{MBq} / \mathrm{kg})$, subsequent $60 \mathrm{~min}$ waiting, and image acquisition of $3 \mathrm{~min}$ per bed position. All scans were reconstructed according to EARL for semi-quantitative analysis [13].

\subsection{Quantification}

Blood pool activity was measured by drawing VOIs within the boundaries of the superior caval vein (SCV) using Hermes Affinity Viewer v2.02 software (Hermes Medical Solutions Inc., Greenville, NC, USA). The SCV was manually delineated on all low-dose $\mathrm{CT}$ slices where the SCV was visible. Manual delineation started cranially at the lower border of the first right costal cartilage (where the left and right brachiocephalic veins end). The SCV was delineated until the first CT slice where the SCV was not distinguishable anymore from the right atrium. After overlaying the co-registered PET image with the low-dose CT, voxels with FDG-uptake spillover from neighboring tissue (i.e., heart tissue or the aortic wall) were carefully excluded from the SCV VOI (see Figure 1 for an example). Delineation was performed by an MD/PhD student with three years of experience with vessel segmentation in PET/CT. The SCV was segmented a second time in a random sample of 10 patients $(25 \%)$ in order to assess intra-observer reliability. 

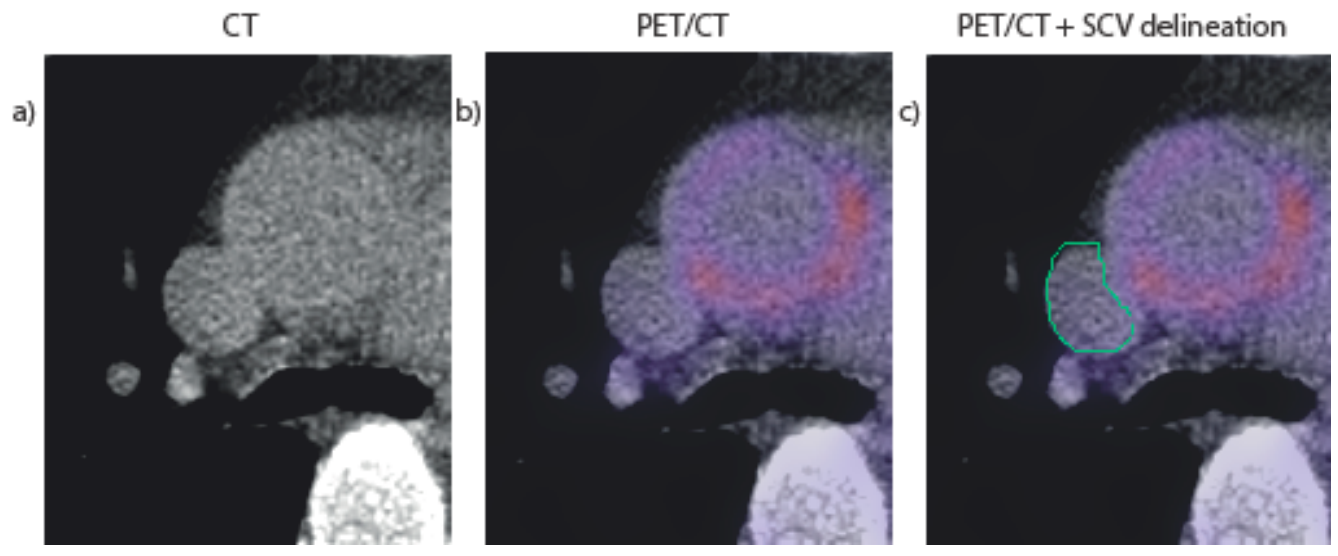

Figure 1. Axial slice of the superior caval vein (SCV) on a CT only (a), on the CT and PET fused (b), and the PET/CT with the SCV manually delineated, while carefully excluded the spillover from the heart next to it $(\mathbf{c})$.

The mean, peak, and maximum standardized uptake value (SUV $V_{\text {mean }}$ and SULmean, $S_{\text {Seak }}$ and $S \mathrm{SL}_{\text {peak }}$, and $S U V_{\max }$ and $S U L_{\max }$ ) of the SCV were chosen as activity parameters. LBM was calculated according to Janmahasatian et al. [14] for male and female, respectively, as recommended in the EANM guidelines for oncological imaging [3]:

$$
\begin{aligned}
& L B M^{M}=9270 \times \frac{\text { body weight }}{6680+216 \times B M I}, \\
& L B M^{F}=9270 \times \frac{\text { body weight }}{8780+244 \times B M I} .
\end{aligned}
$$

\subsection{Statistical Analysis}

Correlation analyses were performed comparing the activity parameters in the SCV according to age, FBGL (mmol/L), fat mass (= body weight - LBM), and estimated glomerular filtration rate (eGFR) calculated using the Chronic Kidney Disease Epidemiology Collaboration (CKD-EPI) equation [15]. Pearson's r was calculated when activity parameters and possible influencing factors were normally distributed. Spearman's $r$ was calculated when activity parameters and possible influencing factors were not normally distributed. Student's t-test or Mann-Whitney U test was done to compare groups (i.e., male vs. female) after testing for normality. After Holm-Bonferroni correction, results were considered statistically significant when $p<0.05$. An intraclass correlation coefficient (two-way random model) was calculated to assess the intra-observer reliability. Coefficients between 0.75 and 1.00 were considered excellent, between 0.60 and 0.74 good, between 0.40 and 0.59 fair, and below 0.40 poor. Statistical tests were performed in Graphpad Prism 8 (GraphPad Software, San Diego, CA, USA) or SPSS (IBM Corp. Released 2015. IBM SPSS Statistics for Windows, Version 23.0. Armonk, NY: IBM Corp.).

\section{Results}

Patients were selected from a prospective cohort with newly diagnosed LVV patients. In total, 43 patients from this cohort underwent an FDG-PET/CT scan at time of diagnosis before start of treatment between 2011 and 2020, and were included in this study. Two patients were excluded because of missing eGFR and height data. Patient characteristics are presented in Table 1. Patient characteristics were equal between female and male patients, except for LBM and fat mass, which were, respectively, lower and higher in females than males. 
Table 1. Patient characteristics of all patients together and female and male separately. Statistically significant $p$-values from comparisons between females and males are highlighted in bold.

\begin{tabular}{|c|c|c|c|c|c|c|c|c|c|c|}
\hline \multirow[b]{2}{*}{$\begin{array}{c}\text { Patient } \\
\text { Characteristics }\end{array}$} & \multicolumn{3}{|c|}{ All Patients } & \multicolumn{3}{|c|}{ Female } & \multicolumn{3}{|c|}{ Male } & \multirow{2}{*}{$\begin{array}{l}\text { F vs. } \mathrm{M} \\
p \text {-Value }\end{array}$} \\
\hline & n [\%] & Mean \pm SD & Range & n [\%] & Mean \pm SD & Range & n [\%] & Mean \pm SD & Range & \\
\hline Number of patients & 41 & & & $26[63.4]$ & & & $15[36.6]$ & & & \\
\hline Age (years) & & $68.6 \pm 8.4$ & $52-89$ & & $68.9 \pm 8.7$ & $52-83$ & & $68.1 \pm 8.1$ & $56-83$ & 0.7968 \\
\hline Weight (kg) & & $76.6 \pm 16.1$ & & & $75.5 \pm 18.1$ & & & $78.4 \pm 12.1$ & & 0.5900 \\
\hline $\operatorname{BMI}\left(\mathrm{kg} / \mathrm{m}^{2}\right)$ & & $26.0 \pm 4.8$ & & & $26.8 \pm 5.3$ & & & $24.5 \pm 3.6$ & & 0.1354 \\
\hline $\mathrm{LBM}(\mathrm{kg})$ & & $50.8 \pm 10.2$ & & & $45.2 \pm 7.4$ & & & $60.5 \pm 6.3$ & & $<0.0001$ \\
\hline Fat mass (kg) & & $25.8 \pm 11.3$ & & & $30.4 \pm 11.1$ & & & $17.9 \pm 6.4$ & & 0.0003 \\
\hline FBGL (mmol/L) & & $6.2 \pm 1.2$ & $4.6-10.8$ & & $6.1 \pm 1.2$ & $4.6-9.2$ & & $6.4 \pm 1.0$ & $5.3-9.2$ & 0.2332 \\
\hline $\begin{array}{c}\text { eGFR } \\
\left(\mathrm{mL} / \mathrm{min} / 1.73 \mathrm{~m}^{2}\right)\end{array}$ & & $82.7 \pm 19.9$ & $37-123$ & & $79.6 \pm 18.2$ & $37-123$ & & $88.0 \pm 22.1$ & $48-123$ & 0.1957 \\
\hline Glucocorticoid naive & $31[75.6]$ & & & 20 [76.9] & & & $11[73.3]$ & & & \\
\hline
\end{tabular}

$\mathrm{SD}$ = standard deviation; $\mathrm{BMI}=$ body mass index; $\mathrm{LBM}$ = lean body mass; FBGL = fasting blood glucose level; $\mathrm{eGFR}=$ estimated glomerular filtration rate.

First, we investigated whether the patient demographics of sex and age influenced the blood pool activity (Figure 2). Blood pool activity measured as $\mathrm{SUV}_{\text {mean }}, \mathrm{SUV}_{\text {peak }}$, and $\mathrm{SUV}_{\max }$ was significantly higher in females compared with males $(p=0.016, p=0.010$, and $p=0.010$, respectively). However, when measured as SULmean, $\mathrm{SUL}_{\text {peak }}$, and $\mathrm{SUL}_{\max }$, no significant differences were found ( $p=0.087, p=0.195$, and $p=0.114$, respectively). No association between age and blood pool activity was found (Table 2 and Figure 3).

Table 2. Pearson's correlation coefficients for age, fat mass, FBGL, and eGFR, with the PET activity parameters. The $95 \%$ confidence intervals are shown between brackets. Significance of the correlations is denoted by $(p<0.05),{ }^{* *}(p<0.01)$, $* * *(p<0.001)$, and $* * * * p 0.0001)$.

\begin{tabular}{|c|c|c|c|c|}
\hline & Age & Fat Mass & FBGL & eGFR \\
\hline $\mathrm{SUV}_{\text {mean }}$ & $\begin{array}{c}0.249 \\
(-0.063 \text { to } 0.517)\end{array}$ & $\begin{array}{c}0.563^{* * *} \\
(0.309 \text { to } 0.742)\end{array}$ & $\begin{array}{c}-0.108 \\
(-0.403 \text { to } 0.206)\end{array}$ & $\begin{array}{c}-0.480 \text { ** } \\
(-0.686 \text { to }-0.202)\end{array}$ \\
\hline $\mathrm{SUL}_{\text {mean }}$ & $\begin{array}{c}0.303 \\
(-0.005 \text { to } 0.559)\end{array}$ & $\begin{array}{c}-0.250 \\
(-0.518 \text { to } 0.063)\end{array}$ & $\begin{array}{c}-0.198 \\
(-0.477 \text { to } 0.116)\end{array}$ & $\begin{array}{c}-0.404 \\
(-0.633 \text { to }-0.110)\end{array}$ \\
\hline$S_{U V V}$ peak & $\begin{array}{c}0.044 \\
(-0.267 \text { to } 0.347)\end{array}$ & $\begin{array}{c}0.574^{* * * *} \\
(0.323 \text { to } 0.749)\end{array}$ & $\begin{array}{c}-0.062 \\
(-0.363 \text { to } 0.250)\end{array}$ & $\begin{array}{c}-0.433^{*} \\
(-0.653 \text { to }-0.144)\end{array}$ \\
\hline$S_{\text {peak }}$ & $\begin{array}{c}0.067 \\
(-0.246 \text { to } 0.367)\end{array}$ & $\begin{array}{c}-0.213 \\
(-0.489 \text { to } 0.101)\end{array}$ & $\begin{array}{c}-0.222 \\
(-0.496 \text { to } 0.092)\end{array}$ & $\begin{array}{c}-0.360 * \\
(-0.601 \text { to }-0.058)\end{array}$ \\
\hline $\mathrm{SUV}_{\max }$ & $\begin{array}{c}0.141 \\
(-0.175 \text { to } 0.430)\end{array}$ & $\begin{array}{c}0.652 \text { ****} \\
(0.430 \text { to } 0.799)\end{array}$ & $\begin{array}{c}0.055 \\
(-0.257 \text { to } 0.356)\end{array}$ & $\begin{array}{c}-0.381 * \\
(-0.617 \text { to }-0.083)\end{array}$ \\
\hline $\mathrm{SUL}_{\max }$ & $\begin{array}{c}0.236 \\
(-0.077 \text { to } 0.507)\end{array}$ & $\begin{array}{c}-0.145 \\
(-0.433 \text { to } 0.170)\end{array}$ & $\begin{array}{c}-0.183 \\
(-0.465 \text { to } 0.132)\end{array}$ & $\begin{array}{c}-0.348^{*} \\
(-0.592 \text { to }-0.045)\end{array}$ \\
\hline
\end{tabular}

SUV = standardized uptake value corrected by body weight; $\mathrm{SUL}$ = standardized uptake value corrected by lean body mass; FBGL = fasting blood glucose level; eGFR = estimated glomerular filtration rate.

Increased fat mass, determined by subtracting the LBM from the total body mass, was associated with increased $\mathrm{SUV}_{\text {mean }}, \mathrm{SUV}_{\text {peak, }}$, and $\mathrm{SUV}_{\max }$ in the blood pool (Figure 4). When correcting for lean body mass by using SUL, no significant correlations were found with fat mass (Table 2)

FBGL was not associated with FDG activity in the blood pool (Table 2 and Figure 5). Conversely, decreased kidney function (in eGFR) was associated with a higher FDG activity in the blood pool (Table 2 and Figure 6). Numerical presentation of the uptake metrics shown in the graphs may be found in the Appendix A.

Intraclass correlation coefficients of two separate measurements by the same observer yielded excellent or good coefficients of 0.86 for $\mathrm{SUV}_{\text {mean }}, 0.71$ for $\mathrm{SUV}_{\text {peak }}, 0.81$ for $\mathrm{SUV}_{\text {max }}$, 0.88 for $\mathrm{SUL}_{\text {mean }}, 0.69$ for $\mathrm{SUL}_{\text {peak }}$, and 0.83 for SULmax. 

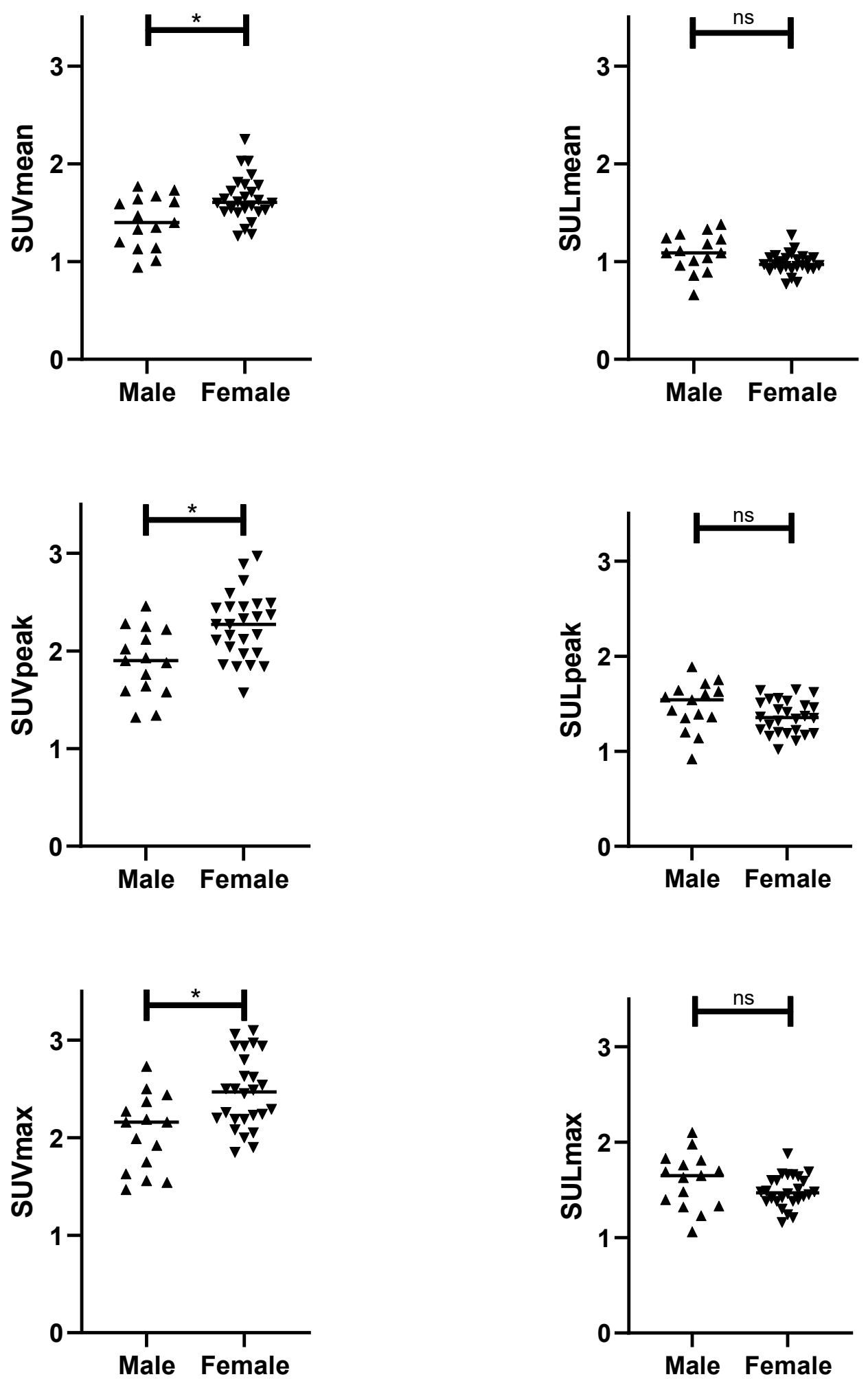

Figure 2. Sex differences in blood pool activity as measured by the mean standardized uptake value (SUV mean), peak standardized uptake value ( $\left.\mathrm{SUV}_{\text {peak }}\right)$, maximum standardized uptake value $\left(\mathrm{SUV}_{\max }\right)$, mean standardized uptake value corrected for lean body mass (SUL mean), peak standardized uptake value corrected for lean body mass $\left(\mathrm{SUL}_{\text {peak }}\right)$, and maximum standardized uptake value corrected for lean body mass (SULmax). Results from t-tests are shown in the graphs, with ${ }^{*}=p<0.05$ and $\mathrm{ns}=$ not significant. 

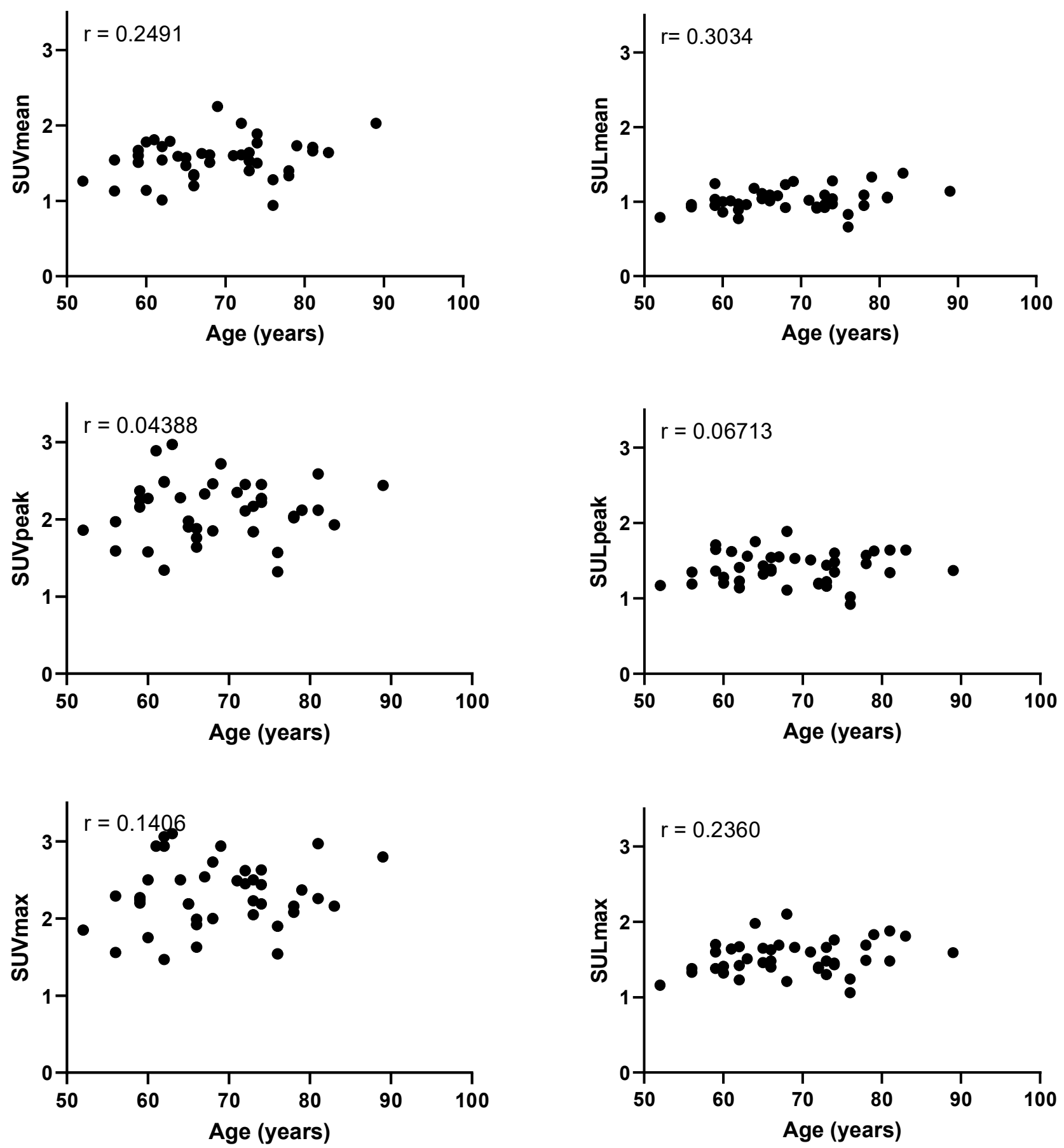

Figure 3. Plots of the patients' ages in years and blood pool activity as measured by the mean standardized uptake value $\left(\mathrm{SUV}_{\text {mean }}\right)$, peak standardized uptake value $\left(\mathrm{SUV}_{\text {peak }}\right)$, maximum standardized uptake value $\left(\mathrm{SUV}_{\text {max }}\right)$, mean standardized uptake value corrected for lean body mass (SULmean), peak standardized uptake value corrected for lean body mass

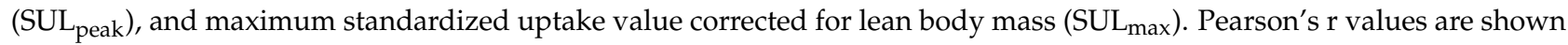
in the upper left corners. None of the correlations were statistically significant $(p=0.582, p=0.785, p=1.000, p=0.323$, $p=1.000, p=0.550$ for $\mathrm{SUV}_{\text {mean }}, \mathrm{SUV}_{\text {peak }}, \mathrm{SUV}_{\text {max }}, \mathrm{SUL}_{\text {mean }}, \mathrm{SUL}_{\text {peak }}, \mathrm{SUL}_{\text {max }}$, respectively). 

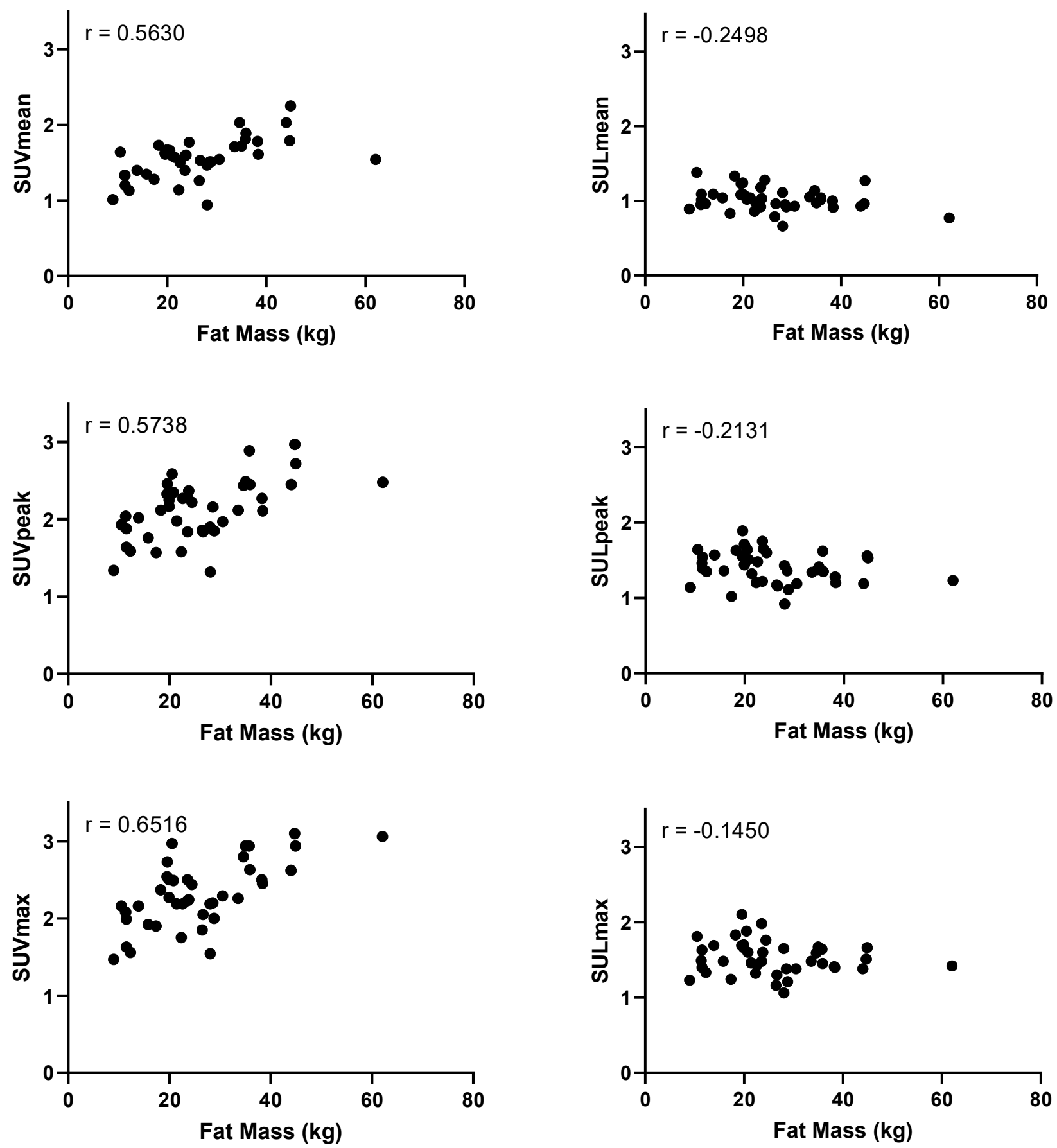

Figure 4. Plots of fat mass in kilograms and blood pool activity as measured by the mean standardized uptake value $\left(\mathrm{SUV}_{\text {mean }}\right)$, peak standardized uptake value $\left(\mathrm{SUV}_{\text {peak }}\right)$, maximum standardized uptake value $\left(\mathrm{SUV}_{\text {max }}\right)$, mean standardized uptake value corrected for lean body mass (SULmean), peak standardized uptake value corrected for lean body mass

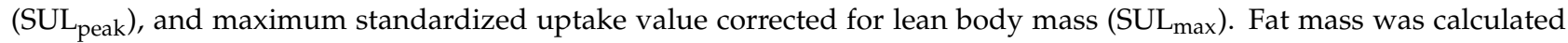
by subtracting the lean body mass from the total body weight. Pearson's r values are shown in the upper left corners, with $p<0.001\left(\mathrm{SUV}_{\text {mean }}\right), p<0.0001\left(\mathrm{SUV}_{\text {peak }}\right), p<0.0001\left(\mathrm{SUV}_{\text {max }}\right)$, and no statistical significance for $\mathrm{SUL}_{\text {mean }}(p=0.346)$, $\operatorname{SUL}_{\text {peak }}(p=0.362)$, and SULmax $(p=0.366)$. 

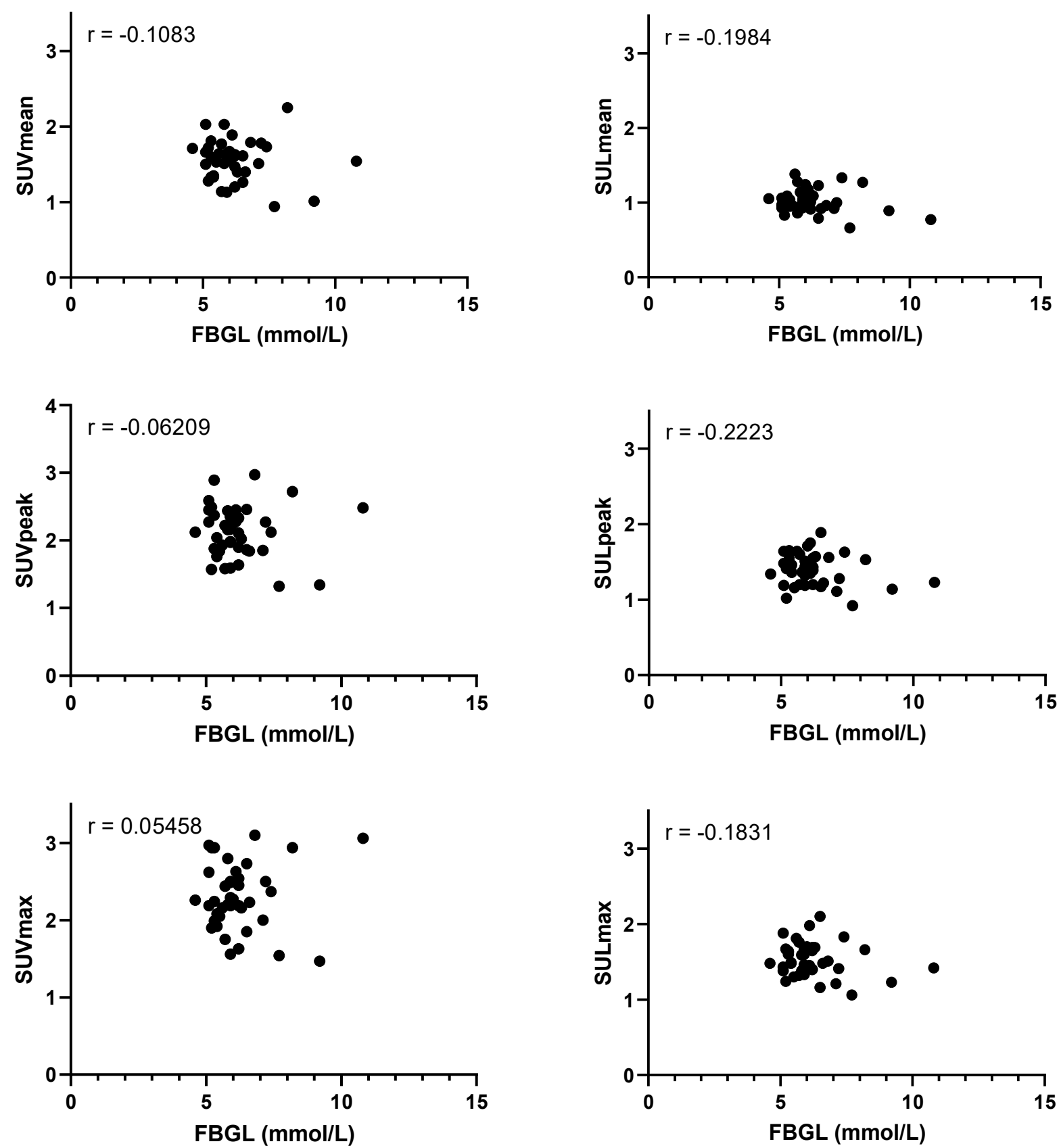

Figure 5. Plots of fasting blood glucose level (FBGL) in mmol/L and blood pool activity as measured by the mean standardized uptake value ( $\left.\mathrm{SUV}_{\text {mean }}\right)$, peak standardized uptake value $\left(\mathrm{SUV}_{\text {peak }}\right)$, maximum standardized uptake value $\left(\mathrm{SUV}_{\max }\right)$, mean standardized uptake value corrected for lean body mass (SULmean), peak standardized uptake value corrected for lean body mass ( $\mathrm{SUL}_{\text {peak }}$ ), and maximum standardized uptake value corrected for lean body mass (SULmax). Pearson's r values are shown in the upper left corners. None of the correlations were statistically significant $(p=1.000$, $p=1.000, p=0.735, p=1.000, p=0.974, p=1.000$ for $\mathrm{SUV}_{\text {mean }}, \mathrm{SUV}_{\text {peak }}, \mathrm{SUV}_{\text {max }}, \mathrm{SUL}_{\text {mean }}, \mathrm{SUL}_{\text {peak }}, \mathrm{SUL}_{\text {max }}$, respectively). 

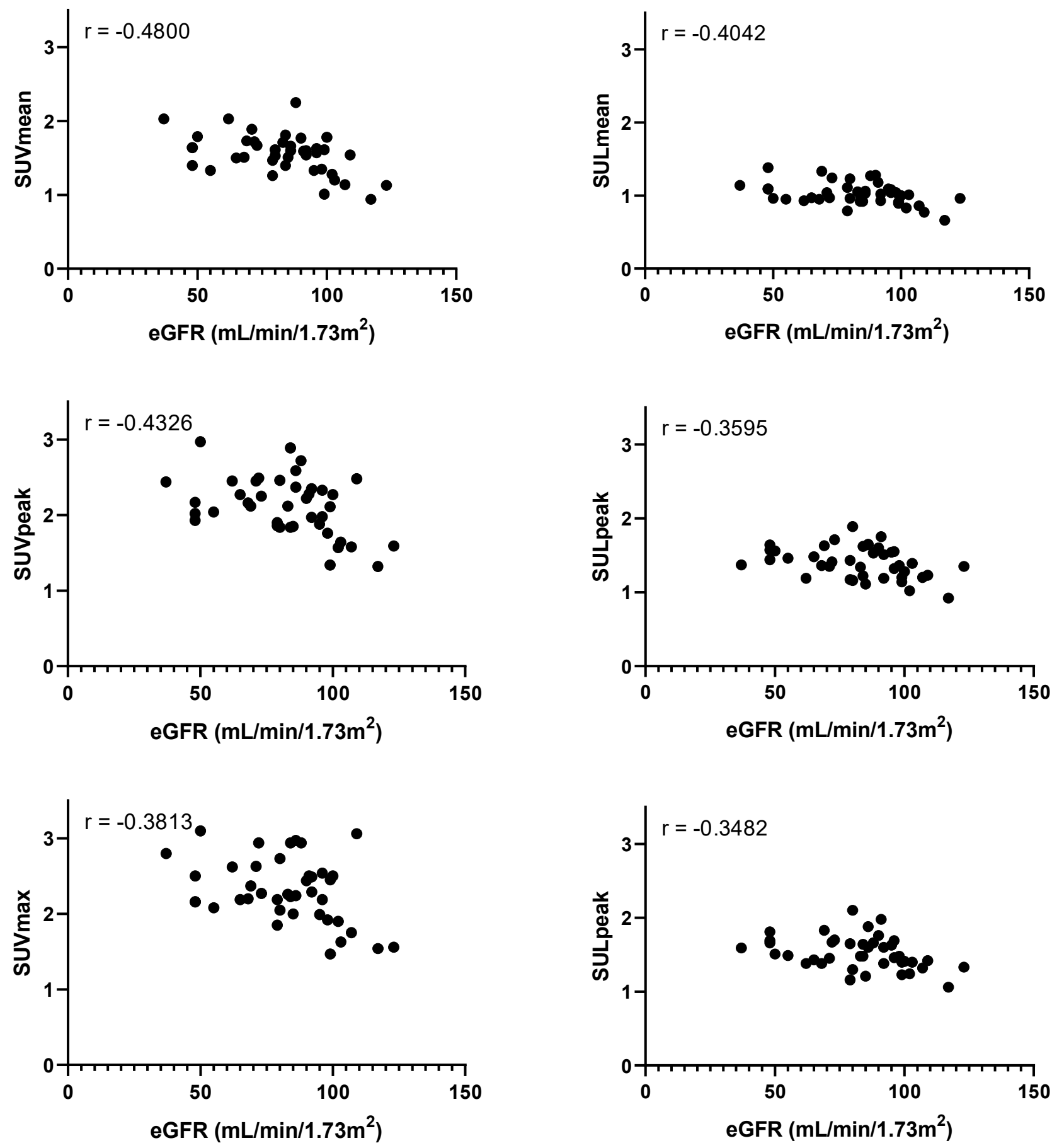

Figure 6. Plots of the estimated glomerular filtration rate (eGFR) and blood pool activity as measured by the mean standardized uptake value ( $\left.\mathrm{SUV}_{\text {mean }}\right)$, peak standardized uptake value $\left(\mathrm{SUV}_{\text {peak }}\right)$, maximum standardized uptake value $\left(S U V_{\max }\right)$, mean standardized uptake value corrected for lean body mass (SULmean), peak standardized uptake value corrected for lean body mass ( $\mathrm{SUL}_{\text {peak }}$ ), and maximum standardized uptake value corrected for lean body mass (SULmax). Pearson's $r$ values are shown in the upper left corners, with $p=0.009\left(\mathrm{SUV}_{\text {mean }}\right), p=0.035\left(\mathrm{SUL}_{\text {mean }}\right), p=0.024\left(\mathrm{SUV}_{\text {peak }}\right)$, $p=0.042\left(\mathrm{SUL}_{\text {peak }}\right), p=0.042\left(\mathrm{SUV}_{\max }\right), p=0.026\left(\mathrm{SUL}_{\max }\right)$.

\section{Discussion}

Guidelines for [18F]FDG-PET/CT imaging in oncological diseases recommend the use of SUL for semi-quantitative analysis instead of the commonly used SUV [3]. In inflammatory diseases there is no consensus regarding which parameter to use for analysis. 
Therefore, we investigated different quantitative measurements (SUV and SUL) for defining the blood pool activity in a specific patient group with LVV. Besides a higher fat mass in female patients compared with male patients, the results showed a significantly higher

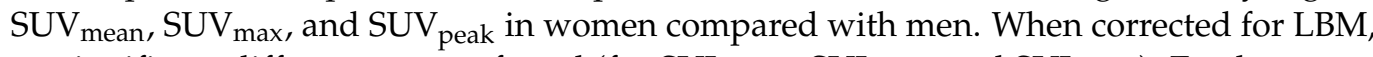
no significant differences were found (for SULmean, SUL max, and SUL ${ }_{\text {peak }}$ ). Furthermore, a significant positive correlation between SUVs and fat mass was found, meaning that a higher fat mass may slow down or reduce the FDG uptake in organs and tissues, thereby subsequently increasing the blood pool FDG activity. To better understand the underlying mechanisms, exact interactions should be investigated in future research. When corrected for LBM (SUL), no correlation was noted. Additionally, no association was found between FBGL and blood pool activity, whereas a negatively proportional correlation was found between eGFR and blood pool activity, meaning that impaired kidney function may result in higher blood pool activity values through reduced renal FDG clearance.

To compare between patients and for consistent treatment strategies it is of utmost importance that imaging metrics correctly reflect the severity of the disease. The population variation of LVV patients, including GCA and Takayasu's arteritis, is large [16]. Large differences in body weight and amount of body fat between and within patients over time may exist, implying that SUV measurements might lead to erroneous interpretation of the (follow-up) results. Our results, although with a small sample size, strongly suggest that the amount of body fat influences the blood pool activity, leading to differences between females and males in SUVs. This could be explained by the fact that, in general, females have a higher percentage of body fat relative to their body weight than men [17]. SUL could thus be a more stable metric, also supported by our findings. This is in line with previous research from Sarikaya et al. which found that SUV overestimates metabolic activity in all patients, but even more in obese patients [18]. SUL, however, is not affected by body fat, and thus more accurate.

Besides SUL, the target-to-background ratio (TBR) is also a metric that may be more reliable in some diseases, especially in therapy follow up studies, and is recommended by guidelines for LVV imaging using blood pool as background [4]. Because TBR is calculated by dividing the SUV or SUL in the target tissue by the SUV or SUL in the background, the correction methods are also divided by each other and thus do not play a role anymore:

$$
T B R=\frac{S U V \text { or } S U L(V O I)}{\text { SUV or SUL(background })} .
$$

Contradictory to previous research [19-21], we did not find any association between FBGL and blood pool activity. This could be explained by the low variance in FBGL of our patient dataset; over $80 \%$ of the patients had an FBGL level lower than $7.0 \mathrm{mmol} / \mathrm{L}$, which was proposed as upper cut-off value whether to perform the [18F]FDG-PET scan at that moment by Bucerius et al. [19].

We did find a negative correlation between blood pool activity values and eGFR. This is in line with results from previous studies. Rosenblum et al. showed in both Takayasu's and GCA patients a negative correlation between blood pool activity and GFR during 1-h imaging [22]. Derlin et al. demonstrated in 50 [18F]FDG-PET scans a significant negative correlation between blood pool SUVs and eGFR [23]. Both studies warn that this could result in overcorrection when TBRs are calculated, as GFR was not associated with FDG uptake in the arterial wall [22,23]. In the same study, Rosenblum et al. showed that at 2-h imaging blood pool activity and TBRs were not associated with GFR anymore [22]. Furthermore, Toriihara et al. found significantly higher uptake values in soft tissues, spleen, and blood pool in chronic renal failure patients compared with the control group with normal kidney function [24]. Laffon et al. even proposed to use a lower [18F]FDG radiation dose in patients with renal failure by using their two-compartment model, which would result in similar uptake values due to the decreased clearance [25]. As stated before, current guidelines do not address this topic concerning the use of [18F]FDG. Some of the abovementioned problems may be eliminated by dynamic or dual time point PET, which should 
be investigated for LVV patients in future research [26,27]. However, as this is currently not clinical practice yet, based on our results, we suggest being cautious with interpreting uptake measurements when patients have impaired renal function.

Our study has some limitations. First, the number of patients included was relatively small. To make recommendations for specific cutoff values in renal function or lower administration of radiotracer dose for example, a larger sample size would be necessary. However, our results coincide with previous research in other diseases and therefore show the importance of consistent scoring in LVV. Second, the variance in FBGL was small and levels itself were mostly low compared with previous proposed cutoff values. Last, only one author delineated the SCVs and therefore interobserver variability analysis was not done. However, intra-observer reliability was rated excellent or good.

In conclusion, fat mass has a significant influence on blood pool SUVs, resulting in differences between sexes. SUL scores are not dependent of the amount of body fat in a patient and thus result in more realistic scores and potentially more consistent treatment strategies than SUV measurements. In addition, eGFR influences blood pool activity in a negative proportional manner. Therefore, we recommend using SUL instead of SUV as quantitative measurement in [18F]FDG-PET scans of patients with LVV and to be cautious with the interpretation of quantitative measurements when patients have impaired renal function.

Author Contributions: Conceptualization, G.D.v.P., P.H.N., D.M.d.J. and R.H.J.A.S.; data curation, P.H.N., D.M.d.J. and M.R.; formal analysis, G.D.v.P. and P.H.N.; funding acquisition, R.H.J.A.S.; investigation, G.D.v.P. and P.H.N.; methodology, G.D.v.P., P.H.N., D.M.d.J., A.T.M.W. and R.H.J.A.S.; project administration, E.B.; Resources, G.D.v.P. and P.H.N.; software, P.H.N. and D.M.d.J.; supervision, R.H.J.A.S.; validation, G.D.v.P. and P.H.N.; visualization, P.H.N.; writing—original draft, G.D.v.P. and P.H.N.; writing—review and editing, D.M.d.J., M.R., K.S.M.v.d.G., E.B., A.W.J.M.G., B.S., A.T.M.W. and R.H.J.A.S. All authors have read and agreed to the published version of the manuscript.

Funding: This work was supported in part by an unconditional grant from PUSH: a collaboration between Siemens Healthineers and the University Medical Center Groningen. The sponsor had no role in the conceptualization, interpretation of findings, writing, or publication of the article.

Institutional Review Board Statement: The study was conducted according to the guidelines of the Declaration of Helsinki and approved by the Ethics Committee of University Medical Center Groningen (METc 2010/222).

Informed Consent statement: Informed consent was obtained from all subjects involved in the study.

Data Availability Statement: The data are not publicly available due to the still ongoing prospective study.

Conflicts of Interest: Gijs D van Praagh: This work was supported in part by an unconditional grant from PUSH: a collaboration between Siemens Healthineers and the University Medical Center Groningen. The sponsor had no role in the conceptualization, interpretation of findings, writing, or publication of the article. Pieter H Nienhuis: Nothing to declare. Daniel M de Jong: Nothing to declare. Melanie Reijrink: Nothing to declare. Kornelis SM van der Geest: Received a speaker fee from Roche paid to the UMCG. Elisabeth Brouwer: As an employee of the UMCG, received speaker fees and consulting fees from Roche in 2017 and 2018, which were paid to the UMCG. Andor WJM Glaudemans: Nothing to declare. Bhanu Sinha: Received a research grant from PUSH, the European Union (Horizon 2020 program), Beatrixoord Foundation, Crossborder Institute, and the Data Federation Hub. Received partial compensation to the department from the Dutch Working Party on Antimicrobial Policy. Antoon TM Willemsen: Nothing to declare. Riemer HJA Slart: Nothing to declare. 


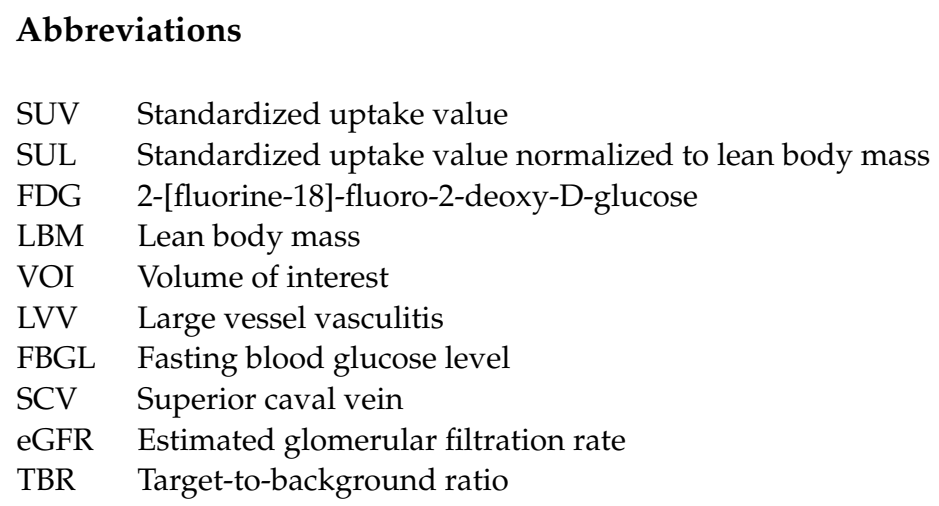

\section{Appendix A}

Table A1. The mean uptake metrics measured in the SCV. The table includes the number of cases/patients (n), the standard deviation (SD), minimum and maximum (range) values.

\begin{tabular}{cccc}
\hline Metric & $\mathbf{n}$ & Mean \pm SD & Range \\
\hline SUV $_{\text {mean }}$ & 41 & $1.554 \pm 0.270$ & $0.940-2.250$ \\
SUV $_{\text {max }}$ & 41 & $2.308 \pm 0.426$ & $1.470-3.100$ \\
SUV $_{\text {peak }}$ & 41 & $2.119 \pm 0.382$ & $1.320-2.970$ \\
SUL $_{\text {mean }}$ & 41 & $1.023 \pm 0.151$ & $0.660-1.380$ \\
SUL $_{\text {max }}$ & 41 & $1.525 \pm 0.223$ & $1.060-2.100$ \\
SUL $_{\text {peak }}$ & 41 & $1.402 \pm 0.213$ & $0.920-1.890$ \\
\hline
\end{tabular}

\section{References}

1. Zasadny, K.R.; Wahl, R.L. Standardized uptake values of normal tissues at PET with 2-[fluorine-18]-fluoro-2-deoxy-D-glucose: Variations with body weight and a method for correction. Radiology 1993, 189, 847-850. [CrossRef]

2. $\quad$ Reijrink, M.; de Boer, S.A.; Spoor, D.S.; Lefrandt, J.D.; Heerspink, H.J.L.; Boellaard, R.; Greuter, M.J.; Borra, R.J.; Hillebrands, J.-L.; Slart, R.H.; et al. Visceral adipose tissue volume is associated with premature atherosclerosis in early type 2 diabetes mellitus independent of traditional risk factors. Atherosclerosis 2019, 290, 87-93. [CrossRef]

3. Boellaard, R.; Delgado-Bolton, R.; Oyen, W.J.G.; Giammarile, F.; Tatsch, K.; Eschner, W.; Verzijlbergen, F.J.; Barrington, S.F.; Pike, L.C.; Weber, W.A.; et al. FDG PET/CT: EANM procedure guidelines for tumour imaging: Version 2.0. Eur. J. Nucl. Med. Mol. Imaging 2015, 42, 328-354. [CrossRef]

4. Slart, R.H.J.A.; Writing group; Reviewer group; Members of EANM Cardiovascular; Members of EANM Infection \& Inflammation; Members of Committees; SNMMI Cardiovascular; Members of Council; PET Interest Group; Members of ASNC; et al. FDGPET/CT(A) imaging in large vessel vasculitis and polymyalgia rheumatica: Joint procedural recommendation of the EANM, SNMMI, and the PET Interest Group (PIG), and endorsed by the ASNC. Eur. J. Nucl. Med. Mol. Imaging 2018, 45, 1250-1269. [CrossRef]

5. Lucignani, G.; Paganelli, G.; Bombardieri, E. The use of standardized uptake values for assessing fdg uptake with pet in oncology: A clinical perspective. Nucl. Med. Commun. 2004, 25, 651-656. [CrossRef] [PubMed]

6. Dashora, H.R.; Rosenblum, J.S.; Quinn, K.A.; Alessi, H.; Novakovich, E.; Saboury, B.; A Ahlman, M.; Grayson, P. Comparing Semi-quantitative and Qualitative Methods of Vascular FDG-PET Activity Measurement in Large-Vessel Vasculitis. J. Nucl. Med 2021, in press. [CrossRef] [PubMed]

7. Angelotti, F.; Capecchi, R.; Giorgetti, A.; Erba, P.A.; Genovesi, D.; Emdin, M.; Barison, A.; Manca, L.; Rocchi, V.; Migliorini, P.; et al. 18-FDG PET for large vessel vasculitis diagnosis and follow-up. Clin. Exp. Rheumatol. 2021, 39, 76-82.

8. Janes, A.L.F.; Castro, M.F.; Arraes, A.E.D.; Savioli, B.; Sato, E.I.; de Souza, A.W.S. A retrospective cohort study to assess PET-CT findings and clinical outcomes in Takayasu arteritis: Does ${ }^{18} \mathrm{~F}$-fluorodeoxyglucose uptake in arteries predict relapses? Rheumatol. Int. 2020, 40, 1123-1131. [CrossRef]

9. Malik, D.; Verma, R.; Gupta, V.; Belho, E.S.; Drolia, B.; Seniaray, N.; Mahajan, H. Semiquantitative interpretation criteria for fluorodeoxyglucose-positron emission tomography/computed tomography in large-vessel vasculitis: Pattern recognition and correlation with polymyalgia rheumatica. Indian J. Nucl. Med. 2020, 35, 6. [CrossRef] [PubMed]

10. Blaak, E. Sex differences in the control of glucose homeostasis. Curr. Opin. Clin. Nutr. Metab. Care 2008, 11, 500-504. [CrossRef]

11. Minamimoto, R.; Takahashi, N.; Inoue, T. FDG-PET of patients with suspected renal failure: Standardized uptake values in normal tissues. Ann. Nucl. Med. 2007, 21, 217-222. [CrossRef] [PubMed] 
12. Van Sleen, Y.; Graver, J.C.; Abdulahad, W.H.; van der Geest, K.; Boots, A.M.H.; Sandovici, M.; Brouwer, E. Leukocyte dynamics reveal a persistent myeloid dominance in giant cell arteritis and polymyalgia rheumatica. Front. Immunol. 2019, 10, 1-13. [CrossRef]

13. Kaalep, A.; Sera, T.; Oyen, W.; Krause, B.J.; Chiti, A.; Liu, Y.; Boellaard, R. EANM/EARL FDG-PET/CT accreditation-summary results from the first 200 accredited imaging systems. Eur. J. Nucl. Med. Mol. Imaging 2018, 45, 412-422. [CrossRef] [PubMed]

14. Janmahasatian, S.; Duffull, S.B.; Ash, S.; Ward, L.C.; Byrne, N.M.; Green, B. Quantification of lean bodyweight. Clin. Pharmacokinet. 2005, 44, 1051-1065. [CrossRef]

15. Levey, A.S.; Stevens, L.A.; Schmid, C.; Zhang, Y.L.; Castro, A.F.; Feldman, H.I.; Kusek, J.W.; Eggers, P.; Van Lente, F.; Greene, T.; et al. A new equation to estimate glomerular filtration rate. Ann. Intern. Med. 2009, 150, 604-612. [CrossRef]

16. Harky, A.; Fok, M.; Balmforth, D.; Bashir, M. Pathogenesis of large vessel vasculitis: Implications for disease classification and future therapies. Vasc. Med. 2019, 24, 79-88. [CrossRef]

17. Deurenberg, P.; Weststrate, J.A.; Seidell, J.C. Body mass index as a measure of body fatness: Age-and sex-specific prediction formulas. Br. J. Nutr. 1991, 65, 105-114. [CrossRef] [PubMed]

18. Sarikaya, I.; Albatineh, A.N.; Sarikaya, A. Revisiting weight-normalized SUV and lean-body-mass-normalized SUV in PET studies. J. Nucl. Med. Technol. 2020, 48, 163-167. [CrossRef]

19. Bucerius, J.; Mani, V.; Moncrieff, C.; Machac, J.; Fuster, V.; Farkouh, M.E.; Tawakol, A.; Rudd, J.H.F.; Fayad, Z.A. Optimizing 18F-FDG PET/CT imaging of vessel wall inflammation: The impact of ${ }^{18} \mathrm{~F}-\mathrm{FDG}$ circulation time, injected dose, uptake parameters, and fasting blood glucose levels. Eur. J. Nucl. Med. Mol. Imaging 2014, 41, 369-383. [CrossRef]

20. Rabkin, Z.; Israel, O.; Keidar, Z. Do hyperglycemia and diabetes affect the incidence of false-negative ${ }^{18}$ F-FDG PET/CT studies in patients evaluated for infection or inflammation and cancer? A comparative analysis. J. Nucl. Med. 2010, 51, 1015-1020. [CrossRef]

21. Zhuang, H.; Cortés-Blanco, A.; Pourdehnad, M.; Adam, L.E.; Yamamoto, A.; Martínez-Lázaro, R.; Lee, J.; Loman, J.; Rossman, M.; Alavi, A. Do high glucose levels have differential effect on fdg uptake in inflammatory and malignant disorders? Nucl. Med. Commun. 2001, 22, 1123-1128. [CrossRef]

22. Rosenblum, J.S.; Quinn, K.A.; Rimland, C.A.; Mehta, N.N.; Ahlman, M.A.; Grayson, P.C. Clinical Factors Associated with Time-Specific Distribution of ${ }^{18}$ F-Fluorodeoxyglucose in Large-Vessel Vasculitis. Sci. Rep. 2019, 9, 15180. [CrossRef]

23. Derlin, T.; Habermann, C.R.; Hahne, J.D.; Apostolova, I.; Klutmann, S.; Mester, J.; Buchert, R. Quantification of $\left[{ }^{18}\right.$ F]-FDG uptake in atherosclerotic plaque: Impact of renal function. Ann. Nucl. Med. 2011, 25, 586-591. [CrossRef] [PubMed]

24. Toriihara, A.; Kitazume, Y.; Nishida, H.; Kubota, K.; Nakadate, M.; Tateishi, U. Comparison of FDG-PET/CT images between chronic renal failure patients on hemodialysis and controls. Am. J. Nucl. Med. Mol. Imaging 2015, 5, 204-211. [PubMed]

25. Laffon, E.; Cazeau, A.L.; Monet, A.; de Clermont, H.; Fernandez, P.; Marthan, R.; Ducassou, D. The effect of renal failure on ${ }^{18}$ F-FDG uptake: A theoretic assessment. J. Nucl. Med. Technol. 2008, 36, 200-202. [CrossRef]

26. Van den Hoff, J.; Hofheinz, F.; Oehme, L.; Schramm, G.; Langner, J.; Beuthien-Baumann, B.; Steinbach, J.; Kotzerke, J. Dual time point based quantification of metabolic uptake rates in ${ }^{18}$ F-FDG PET. EJNMMI Res. 2013, 3, 1-11. [CrossRef] [PubMed]

27. Blomberg, B.A.; Bashyam, A.; Ramachandran, A.; Gholami, S.; Houshmand, S.; Salavati, A.; Werner, T.; Zaidi, H.; Alavi, A. Quantifying $\left[{ }^{18} \mathrm{~F}\right]$ fluorodeoxyglucose uptake in the arterial wall: The effects of dual time-point imaging and partial volume effect correction. Eur. J. Nucl. Med. Mol. Imaging 2015, 42, 1414-1422. [CrossRef] 